\title{
Making Smart Regions Smarter: Smart Specialization and the Role of Universities in Regional Innovation Ecosystems
}

\author{
Markku Markkula and Hank Kune
}

\author{
"When you come to a fork in the road, take it." \\ Yogi Berra (1925-2015) \\ Baseball player, manager, and coach
}

\begin{abstract}
What makes a "smart region" smarter? We argue that it is the active orchestration of the regional ecosystem around concepts such as knowledge co-creation and exploitation, opportunity exploration, and capacity building. Simply adding to the proliferation of software developers in the area, stimulating the activities of business clusters around information technology, and providing digitally enabled services for citizens is not enough to make a region smarter. Smartness is enhanced by a well-orchestrated regional innovation ecosystem with a strong "smart specialization strategy" that leverages the new societal roles played by universities. In this article, we describe the European Commission's program for research and innovation strategies for smart specialization (RIS3) and show how the Helsinki Region in Finland is using smart specialization, ecosystem orchestration, and the active role of universities to enhance regional innovation and the "smartness" of the region. These activities are discussed in the context of policy documents and strategy papers from regional, national, and European authorities, which illustrates some differences between papers and practice. This is work in progress, and based on early results, we draw initial conclusions about how putting policy into practice can make smart regions smarter.
\end{abstract}

\section{Introduction}

These days, the world is full of "smart cities" and "smart regions". They proliferate rapidly as new digital technologies are applied to enhance daily life. Smartness is "in", it is "cool", and the labels proliferate. Yet, this labelling often masks the real challenges of smart regions and smart citizens living in smart societies. How can we make so-called smart regions smarter? What do residents need to be able to survive, and thrive, in smart regions? What is the nature of smartness? Is it simply a matter of more software developers in the area, the activities of business clusters around information technology, and the provision of digitally enabled services for citizens? Or is there more to it?

The "smartness" of a region relates to its capacity to leverage its human, structural, and relational capital, and its ability to integrate diverse actors in the region's innovation practice. Leveraging regional strengths and capacities in relation to Europe's program for research and innovation strategies for smart specialization (RIS3) is essential. The contribution of universities, in their diverse roles, is especially important. In many countries, universities are taking an increasingly active role in regional development, and at the interface of universities, industry, public authorities and citizens the major Quadruple Helix actors in the regional innovation ecosystem - concepts such as knowledge co-creation and exploitation, opportunity exploration, and capacity building have become important enablers of innovation. In this article, we argue that leveraging the new "third role" of universities is essential for maintaining smart and effective regional innovation ecosystems.

Smart specialization is Europe's transformation agenda for the next decade, and it requires a well-orchestrated regional ecosystem to work effectively. Within this constellation, notions of knowledge creation and the translation of knowledge into practice are becoming 


\section{Smart Specialization and the Role of Universities in Regional Innovation Ecosystems} Markku Markkula and Hank Kune

increasingly important and are taking new forms. Europe needs entrepreneurial and pioneering regions with practices that integrate top-down policy making with bottom-up self-renewal to create effective policy. Diverse European documents and policy papers attest to these needs (CoR, 2013). Smart specialization aims to support regions in addressing this challenge. In these regions, all societal partners need to work together, and joint learning is a cornerstone of this collaboration. Universities are an important instrument for codifying the lessons learned and helping other actors take the learning to the next level of practice. They are beginning to play this role in regional innovation ecosystems, making smart regions smarter and supporting diverse regional players in collaborating effectively. This is the context called for in diverse policy papers and strategy documents. In this article, we describe how this works in practice, focusing on the contributions universities make to smart regions, and using the experiences of Finland's Helsinki Region in creating and realizing its smart specialization process.

\section{Moving Towards Smarter Regions}

The notion of smart cities and regions is not new. Since the 1990s, cities and regions looked at ways to enhance quality of life through technology and often eagerly adapted the "smart" label to describe activities aimed at enhancing effective city management, economic development, and prestige. This "tools and technology approach" has produced some impressive results, but is now seen as flawed in several ways: it starts with technology rather than urban challenges, there is insufficient use or generation of evidence of what actually works to address real-world challenges, and there is little citizen engagement (NESTA, 2015).

In this article, we consider "smartness" to constitute the effective interplay and reciprocity of thinking capacity and technology in improving the quality of life in the region. Smartness is seen - at the level of "smart citizens" - as the ability to understand and use knowledge effectively and the capacity to use digital media to create added value in daily (working) life. Hardware and software alone are not the answer, and "smartness" in the more traditional sense of the word: the capacity (of individuals, organizations, and regions) to understand and process knowledge, create new knowledge, and translate this knowledge into practice. This capacity can and should be supported by information and communication technologies, but it resides first and foremost in people's ability to think and to apply thinking skills effectively. Universities, in their core capacity of facilitating learning, are essential for this approach to be effective.

Regions recognize that the role of universities and the importance of scientific research in tackling these challenges are increasing, but the question of how to quickly and effectively transform research knowledge into practical applications still poses a major concern. The region's ability to learn, the practice of organizational learning, and the ability to conduct research and innovation in multi-dimensional teams and networks are basic requirements of modern societies. This is part of what makes regions "smart". But, both the importance and the difficulty of learning increase significantly in larger regional innovation ecosystems (Lappalainen et al., 2015).

The interface of regional players in the regional innovation ecosystem - from business, government, universities, and civil society - is where the exploration and potential application of knowledge can most powerfully be exploited. Effective collaboration there determines how smart a region can be, and how to leverage its potential. It defines the quality and effectiveness of the regional innovation ecosystem. In many cases, this task is not easy, and effective collaborate of societal partners is often a serious challenge. In order to address this, the European Union has actively embraced the concept of regional research and innovation strategies based on smart specialization - the so-called research and innovation strategies for smart specialization (RIS3). RIS3 provides a regional policy framework and basis for innovation-driven growth. RIS3 must be seen as a process of entrepreneurial discovery: an interactive and innovative process in which market forces and the private sector together with universities discover and produce information about new activities, and the government assesses the outcomes and empowers those players most capable of realizing the potential (Foray et al., 2012). RIS3 are much more bottom-up than traditional industrial policies. In the next section, we ask: How does this strategy translate into practice?

\section{Actors in the Ecosystem}

International competitive edge is increasingly based on a shared intent of the key regional actors to turn an area into a significant innovation hub, and for selected themes, even an innovation frontrunner (Launonen \& Viitanen, 2011). All innovation hubs, which are also innovation ecosystems, have four factors in common: 


\section{Smart Specialization and the Role of Universities in Regional Innovation Ecosystems}

\section{Markku Markkula and Hank Kune}

1. They have globally valued special expertise and corporate activities based on this expertise.

2. They create new knowledge that is applied on a global scale.

3. The hub attracts international expertise, competencedriven business and investments.

4. They have companies of excellence that operate both locally and globally.

Collaboration forms are needed to define organizational aims and needs in the context of the ecosystem, and to describe what is required to enable the required quality to be delivered. These aims and criteria drive regional actors to apply their competence in regional projects. The general level of competence required from companies, universities, and societal operators must be identified for each effort. This effort also requires modernizing the triple helix concept, which was developed in the 1990s to emphasize the need for collaborative contributions by three actor groups: industry, government and other public-sector organizations, and universities (Etzkowitz \& Ranga, 2011). Although discussions around a quadruple helix and even a quintuple helix have become more common in recent years, the reality of actual collaboration in many countries is still very much a work in progress, and in many regions, sometimes even triple helix collaboration is difficult to achieve.

Finland has a long tradition in co-creation and effectively implementing the triple helix model, and its citizens are traditionally actively engaged in public-sector processes. Quadruple helix thinking and operations are a natural means to speed up innovation in the Helsinki Region. This affinity with participative processes is clearly seen in the ecosystem-thinking model developed there (Lappalainen et al., 2015).

Even in Finland, modernizing the triple helix in RIS3 processes means going one step further: focusing on the regional innovation ecosystem and the use of ecosystem thinking to consider which actor groups are relevant in societal change processes. In the triple helix, industry operates as the locus of product development and production, government as the source of contractual relations that guarantee stable interactions and exchange, and the university as a source of new knowledge and technology. This is certainly the case in the Helsinki Region. The quadruple helix adds citizens to the mix: as end users of products and services, but also as contributors and co-creators of new knowledge from their own areas of expertise. Smart specialization strategies must be developed through an "entrepreneurial discovery process", in direct consultation with all ecosystem actors, including citizens (Foray et al., 2012). In this way, RIS3 become a bottom-up process of exploration and discovery.

Six principles underlying the triple helix have been elaborated, each bringing a specific exploration focus for orchestrating regional innovation ecosystems:

1. Actors: How does the cooperation between universities, industry, and public administration function in the region?

2. Structures: Structures, networks, research groups, and jointly steered organizations emerge at the interfaces of collaboration. What is their status?

3. Premises: What premises are available for physical, virtual, and social development?

4. New organizations: New actors often represent hybrids that integrate elements from different institutions, such as science parks and corporate and technology incubators. Have new actors emerged in the region?

5. Knowledge and technology transfer and co-creation: How do the different innovation, invention, and patent services within universities and research institutes, knowledge-intensive business services (KIBS), incubators, and investor organizations function?

6. Policies: Are new financing instruments, collaboration support, intellectual property right measures, and reforms, taxation or regulation in place?

These are excellent questions, but not all of the relevant actors are considered. Experience shows that the citizen is an equally important actor (Irvin \& Stansbury, 2004).

The triple helix model is no longer enough in the context of smart specialization. For working in a quadruple helix context, we propose a seventh principle:

7. Participation: What role does the knowledge base and expertise of engaged citizens play in making the regional innovation ecosystem smarter? 


\section{Smart Specialization and the Role of Universities in Regional Innovation Ecosystems}

\section{Markku Markkula and Hank Kune}

Each region, of course, has its own renewal needs and challenges when developing as an innovation ecosystem, but a complex mix of factors like these forms the basis of any regional innovation ecosystem. As the roles and responsibilities of these institutional spheres change, each - in its own way - has been focusing more than ever on the active engagement of citizens as innovation developers and users. The evolution of recent years can be described as a systemic change (Markkula, 2014). In the broad spirit of innovation at the basis of RIS3, significant flexibility, adaptation of processes, acquisition of new skills, and the potential re-distribution of power among organizations are required (Carayannis et al., 2012). These competences and mindsets can be learned, but not necessarily in the classrooms of traditional universities. Learning by doing and coached practice are relevant here, as are new forms of university curricula and diverse new notions of the modern university such as the "entrepreneurial university" (Etzkowitz et al., 2012) and the "civic university" (Goddard, 2009).

\section{Changing Roles for Universities}

The way universities function is changing, as different universities explore how to fill in their "third role". In pioneering regions across Europe, universities are becoming active players in their communities, contributing to the quality of life and regional well being, adding value to regional development processes, and anchoring the importance of knowledge in the regional innovation ecosystem. Ideally, this is a co-creation process producing regional services in collaboration with industry, public authorities, and citizens. In practice, the role of universities across Europe differs from region to region, but in the best instances, universities have an essential role in infusing the region with knowledge, resources, and co-creation and renewal capabilities. The universities and research centres operating actively within the Helsinki Region and Espoo Innovation Garden developments - especially Aalto University, Helsinki University, VTT Technical Research Centre of Finland, Laurea University of Applied Sciences, and Metropolia University of Applied Sciences - are good examples of this. Traditionally, universities play societal roles relating to disseminating knowledge, discovering new knowledge, and societal participation. The importance of the third role is expanding, and requires universities to rethink how this can most effectively be fulfilled. The smart specialization process development in the Helsinki Region offers an example of how this is possible.
In addition, universities have been required to play many new roles in recent years. The role of knowledgeexchange platform provider is of increasing importance. This role will include the following elements:

1. Connection: Connecting generations (students, lifelong learners, and reaching out to work more closely with primary and secondary schools in developing competences in discovery learning); connecting people to processes (encouraging engagement and active contribution to societal processes); connecting knowledge to processes (regional, social, and societal learning processes); and connecting ecosystem partners to each other;

2. Knowledge: Infusing the region with knowledge and understanding, and enhancing smartness and intelligence in the older senses of thinking and knowing.

3. Learning: Not simply curriculum-based, but learning from practice, learning in the ecosystem (and also about the ecosystem), and making this learning accessible throughout the ecosystem.

4. Anticipating: We need facilities to deal with problems and issues before they become acute. Most regional challenges of today (could) have been anticipated in the past and addressed earlier. Universities should maintain proactive foresight, fore-search, and earlywarning facilities for the regions and the communities they serve.

5. Generations of the future: Helping young people to prepare for the opportunities of many possible futures as they are emerging: guiding, coaching, condition-creating, competence-enhancing, and capacity building.

The emerging third role of universities can be seen clearly in the RIS3 process development and strategy implementation in the Helsinki Region.

The European Union's Smart Specialization Platform breaks down the active regional contributions by universities into four areas:

1. Business innovation: closely linked, although not exclusively, to the research function of the university

2. Human capital development: linked to the teaching function 


\section{Smart Specialization and the Role of Universities in Regional Innovation Ecosystems}

\section{Markku Markkula and Hank Kune}

3. Community development: linked to the public service role of universities

4. Institutional capacity of the region: the university contributes through engagement of its management and members in local civil society

Where these four domains are integrated, the university can be seen to be occupying a proactive and not just a passive role in the regional development process (Goddard, 2011).

The City of Espoo and Aalto University show how they operate in all four domains. In the Helsinki Region, Aalto University is a globally connected university, which acts as a "window on the region", bringing fresh ideas in and engaging in diverse activities that build and enhance the image and reputation of the region to the wider world. Universities, business communities, and other public sector authorities have demonstrated their commitment to the process by investing in their own development. The European Commission's guide, Connecting Universities to Regional Growth (Goddard, 2011), bridges three knowledge and policy domains education, research, and innovation - which is the socalled "knowledge triangle" (Markkula, 2013).

Universities play a strategic role by pulling together all their know-how to create greater economic and social impact. There is much to learn from how regions integrate the potential of universities in their development processes, and how universities actively choose different ways to manage their resources for fulfilling their traditional roles as knowledge creators and disseminators, creating new opportunities for researchers, learners, and teachers. The traditional role of universities has given way to collaborative models recognizing the important third mission or third role of universities: civic engagement and societal participation to support communities in tackling diverse social and societal challenges (EUA, 2014).

In the Helsinki Region, three kinds of contribution characterize this new societal participation. The first contribution of universities is driven by a new understanding of the importance of applying research in practice. This contribution requires an active science-society dialogue in which universities, local government, non-governmental organizations (NGOs), industry, and citizens become aware of and alert to each other's needs and potential contributions. There are diverse experiments with this science-society dialogue in the Helsinki Region. On the one hand, regional development projects with specific challenges and problems are looking for answers, and relevant research into the potential solutions may well exist. Recognizing the importance of bridging the gap between science and society is an essential step in this process; it requires: “...a good understanding on both sides of what research there is, what issues are being discussed, and how relevant research can impact on local and regional issues" (CoR, 2013). This dialogue can lead to faster and more effective societal solutions. However, linking the world of research and science with the world of business and government often requires a kind of two-way mediating service; these worlds use different languages and often are not able to easily access and understand the language spoken in the other world, however relevant the message may be (CoR, 2013). This mediation service requires further development and active implementation, using all the resources of the "knowledge triangle" (i.e., research, education, and innovation activities), in order to further strengthen the societal role of universities.

All societal challenges have a strong local dimension, which can be of benefit when scientists become aware of the real issues and burning questions faced by their societal partner, and societal stakeholders understand what science and research can offer for understanding complicated and complex issues. Diverse target groups in different regional and cultural environments - scientists, civil servants, small and medium-sized businesses (SMEs), and students - need to be coached in understanding and actively complementing each other's perspectives, and in how to apply relevant ideas in practice. Universities can play a particularly crucial role here. In many ways, this coaching is an extension of what universities normally do with learners, and initiating and maintaining this science-society dialogue takes academics out into society and brings societal stakeholders into the university, enriching the urban experience of all parties.

The second contribution universities make in their societal participation role reflects the importance of entrepreneurship and entrepreneurial discovery in feeding regional development. The spirit of entrepreneurial discovery drives innovation in the regional ecosystem, creating conditions in which researchers, students, civil servants, and SMEs can all become more alert to promising opportunities, developing or discovering new ideas or opportunities for the purpose of creating value, be it economic, social, or even political. Entrepreneurial discovery is a mindset characterized by curiosity, creativity, courage, and direct practice, all applied in discovering how to act to improve quality of life. Entre- 


\section{Smart Specialization and the Role of Universities in Regional Innovation Ecosystems} Markku Markkula and Hank Kune

preneurial discovery means experimentation and risk taking, and it can also mean failing. It requires people and organizations to work together in ways that strengthen the ecosystem. The many examples of entrepreneurial discovery by students and researchers in Aalto and Espoo Innovation Garden illustrate the importance of this contribution (Markkula \& Kune, 2015).

The third contribution of universities to smart specialization and smart regions relates to the university's roles as knowledge creators and disseminators. Universities educate people and prepare them for taking part in society, for actively engaging and contributing their talents and qualities to build smarter regions, and for understanding, adopting, and using the many innovative products and services these regions need in order to prosper. Smart regions need smart citizens - smart in the deeper sense of knowing things, having and showing intelligence, understanding and applying knowledge, and being able to think sharply and quickly in difficult situations. Open minds are a precondition for innovation. This view reflects the intention of education, be it primary, secondary, tertiary, or lifelong learning. Together, these three contributions to smart regions are a powerful expression of good governance in the 21st century (Markkula \& Kune, 2015).

The Helsinki Region intends to fulfill its pioneering role as a leading global innovation hub, where the knowledge triangle - research, education, and innovation activities - is fully integrated in practice, and where both entrepreneurial discovery and startup mentality are visibly valuable in university-industry-government collaboration. This induced synergy helps achieve a far greater impact than ordinary development measures would allow (Markkula, 2013).

\section{Smart Specialization in the Helsinki Region}

As the leading national expertise cluster, the Helsinki Region is at the strategic core of Finland's international competitiveness. It is the economic heart of the small and open economy of Finland. The region consists of the Cities of Helsinki, Espoo, and Vantaa and 23 other municipalities around it. The main cities have a joint competitiveness programme, as well as different collaborative arrangements for water management and public transport and various informal networks as grounds for active co-operation (EKA, 2014).

The aim of the Helsinki Region's smart specialization strategy is to promote sustainable regional development. The vision is for the Helsinki Region to be inter- national innovation hub by 2020, and to double its research and innovation activities. In addition, the working culture should be agile, networked, and proactive. To achieve this goal, more investments are needed from abroad, as well as a significant increase in labour immigration and a creative and versatile cultural platform developed in which business based on creative expertise strengthens the regional economic structure and employment (EKA, 2014). As a policy instrument, smart specialization is a continuous process, and the region recognizes that, in order to move towards achieving its vision, a flexible and adaptive approach to the implementation of its strategy is required. When successful, it can open up important opportunities for joining forces, matching roadmaps, and building more world-class clusters.

In the Helsinki Region, RIS3 process development was carried out step by step, using the S3 Platform guidebooks (Foray et al., 2012). The smart specialization strategy helps to focus the region on its key themes, endeavours, and partnerships. Research and innovation activities have been developed in collaboration platforms and promoted with policy and financing instruments. Success will be based on the new working culture, and the effect of orchestration concepts developed for mobilizing actors to operate in digitalized open innovation platforms. In Figure 1, we can see the five regional spearheads and how they interface with RIS3 priorities. This concept has been developed together with all regional stakeholders, including industry, universities, the region and its diverse cities, as well as with citizens. The most challenging tasks are to create the digitalized innovation platforms for collaboration and to motivate the actors in the region for this collaboration. Each of the five spearheads - at the bottom of the figure - consists of many activities orchestrated as a single synergic endeavour. In practice, one or several project portfolios will be formed for each spearhead theme.

University research plays an important role in each of these spearheads. The four-year regional development research program "Energizing Urban Ecosystems" with Aalto University as a key partner - has raised awareness of the regional innovation ecosystem among regional actors (Markkula \& Kune, 2013). The Aalto Camp for Societal Innovation (ACSI) has been used to support the networked cooperation between regional innovation hotspots in 2013, and in 2015 it will help define priorities for the "Smart Citizen" spearhead (2015). Early results can be seen in the diverse regional activities initiated around the five spearheads. 


\section{Smart Specialization and the Role of Universities in Regional Innovation Ecosystems}

\section{Markku Markkula and Hank Kune}

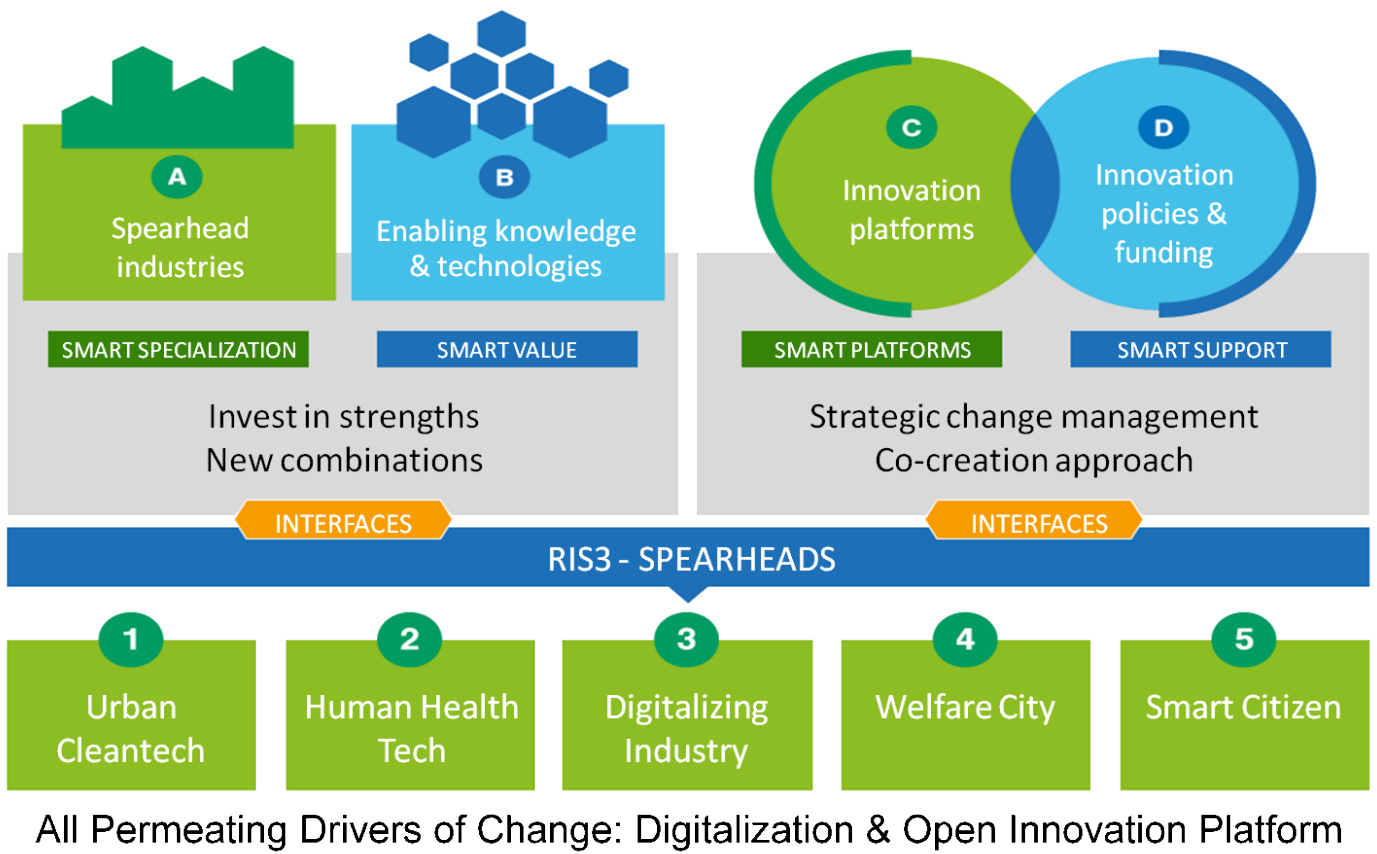

Figure 1. The concept of the Helsinki Region smart specialization strategy is an ongoing systemic process based on the orchestration of all the key innovation policy actors in the region. Reproduced from the Helsinki-Uusimaa Regional Council (2014).

\section{Conclusions: Infusing the Region with Knowledge}

Europe is facing grand societal challenges in an era of globalization and digitalization. Mere market forces alone cannot address these challenges adequately, and in many cases they actually exacerbate societal problems. A collaborative, co-creative approach involving all societal actors is required for realizing a regional policy that focuses on creating new opportunities for enhancing growth, competition, and quality of life in the region. This approach also includes new opportunities to involve universities as collaborators in reframing issues and seeking solutions. RIS3, as applied in the Helsinki Region, is an important driver for this effort.

Both official documents from European Commission and the Helsinki Region's experience stress the importance of societal capital for the renewal of regions. The European Union's smart specialization policy aims to address this challenge. In modernizing the triple helix and instituting ecosystem thinking, pioneering regions can better address societal challenges and apply excellence in science and industrial leadership in dealing with important issues. The direct involvement of stakeholders from industry, universities, and the public sec- tor, and the engagement of citizens in co-creative work processes, is a prerequisite for the success of smart regions, and it is the key to translating the regional potential into better quality of life. Through their active roles in the creative translation of potential into practice, universities are essential for infusing the region with knowledge.

In order to thrive, regions require the development of attractive places to work and live - and an enabling factor is experimenting with the regional concept of innovation platforms to address their smart specialization spearheads. Universities can help regions make effective use of the diverse societal-dynamic models available for improving their development processes and their societal services. In the regional innovation ecosystem, all actors can use the research and innovation base of universities for producing services and other products that societies need. In this way, new avenues are opened for co-creating and inventing the future we desire.

A university's capacity to reach out to regional business and the community will fail if the region does not have sufficient capacity for in place innovation. This challenge is particularly acute in less favoured regions, 


\section{Smart Specialization and the Role of Universities in Regional Innovation Ecosystems}

\section{Markku Markkula and Hank Kune}

where increasing the innovation capacity of the region is the only way to create the necessary preconditions for growth and success. In relatively prosperous regions, the reach-out is easier, but never a given; this role has to be proudly pursued and actively defended. Knowledge creation, dissemination, and use are essential for keeping regions smart. Joint learning is a cornerstone of the collaboration in the ecosystem, and - as is being shown in the Helsinki Region - universities have a key role to play in making smart regions smarter.

\section{About the Authors}

Markku Markkula is the President of the European Union Committee of the Regions (CoR), where he has been a member since 2010 and Rapporteur on several opinions related to topics such as Europe 2020, digitalization, single markets, as well as research and innovation. His experience includes memberships of several High Level Expert Groups, and he is a member of the EU Smart Specialisation Mirror Group. Markku works within Aalto University as the Advisor to Aalto Presidents, focusing on European Union strategy affairs. His previous work experience includes Directorship of the Lifelong Learning Institute Dipoli and the Secretary General of the International Association for Continuing Engineering Education IACEE. He is a former member of the Finnish Parliament (1995-2003). As an MP, his international role included the Presidency of EPTA Council (European Parliamentary Technology Assessment Network). In the Helsinki Region, he is the Board member of the Regional Council and the chair of the Steering Board, which makes decisions on the use of Structural Funds. He is a longstanding Espoo City Council member, as well as the chair of the City Planning Board.

Hank Kune is Director of Educore BV, Founding Partner and member of the governing board of the Future Center Alliance, and active member of the New Club of Paris, a global network organization working as agenda developer for knowledge societies, where his focus is on entrepreneurial initiatives and societal innovation coaching. Hank works with diverse corporate and government organizations in projects about societal innovation and renewal, with a special emphasis on hands-on problem solving in complex social, societal, and organizational situations.

\section{References}

Carayannis, E., Barth, T., \& Campbell, D. 2012. The Quintuple Helix Innovation Model: Global Warming as a Challenge and Driver for Innovation. Journal of Innovation and Entrepreneurship, 1(2). http://dx.doi.org/10.1186/2192-5372-1-2

CoR (Committee of the Regions). 2013. Opinion of the Committee of the Regions on "Closing the Innovation Divide". Official Journal of the European Union, 56(C218): 12-21. http://dx.doi.org/10.3000/1977091X.C_2013.218.eng

EKA (Project Helsinki as Forerunner Area). 2014. Helsinki Smart Region: Pioneering for Europe 2020, 2nd Ed. Helsinki: EKA B Project / Helsinki-Uusimaa Regional Council.

Etzkowitz, H., \& Ranga, M. 2011. "Spaces”: A Triple Helix Governance Strategy for Regional Innovation. In A. Rickne, S. Laestadius, \& H. Etzkowitz (Eds.), Regional Innovation Systems: The Swedish Experience of Policy, Governance and Knowledge Dynamics. London: Routledge.

Etzkowitz, H., Ranga, M., \& Dzisah, J. 2012. Wither the University? The Novum Trivium and the Transition from Industrial to Knowledge Society. Social Science Information, 51(2): 143-164.

http://dx.doi.org/10.1177/0539018412437099

EUA (European University Association). 2014. The Role of Universities in Smart Specialisation Strategies: Report on Joint EUA-REGIO/JRC Smart Specialisation Platform Expert Workshop. Brussels: EUA Publications.

Foray, D., Goddard, J., Beldarrain, X. G., Landabaso, M., McCann, P., Morgan, K., Nauwelaers, C., \& Ortega-Argiles, R. 2012. Guide to Research and Innovation Strategies for Smart Specialisation (RIS 3). Brussels: European Commission Smart Specialisation Platform.

Goddard, J. 2009. Re-Inventing the Civic University. London: Nesta.

Goddard, J. 2011. Connecting Universities to Regional Growth: A Practical Guide. Brussels: European Commission Smart Specialisation Platform.

Helsinki-Uusimaa Regional Council. 2014. Smart Specialisation in the Helsinki-Uusimaa Region: Research and Innovation Strategy for Regional Development 2014-2020. Helsinki: Helsinki-Uusimaa Regional Council.

Irvin, R., \& Stansbury, J. 2004. Citizen Participation in Decision Making: Is it Worth the Effort? Public Administration Review, 64(1): 55-64. http://dx.doi.org/10.1111/j.1540-6210.2004.00346.x

Lappalainen, P., Markkula, M., \& Kune, H. (Eds). 2015. Orchestrating Regional Innovation Ecosystems: Espoo Innovation Garden. Espoo: Aalto University in cooperation with Laurea University of Applied Sciences and Built Environment Innovations RYM Ltd.

Launonen, M., \& Viitanen, J. 2011. Hubconcepts: The Global Best Practice for Managing Innovation Ecosystems and Hubs. Helsinki: Hubconcepts Inc.

Markkula, M. 2013. The Knowledge Triangle Renewing the University Culture. In P. Lappalainen \& and M. Markkula (Eds.), The Knowledge Triangle: Re-Inventing the Future: 11-31. European Society for Engineering Education (SEFI), Aalto University, and Universitat Politecnica de Valencia.

Markkula, M. 2014. Renewing the Triple Helix in a Context of Smart Specialisation. Helice, 3(1). 


\section{Smart Specialization and the Role of Universities in Regional Innovation Ecosystems Markku Markkula and Hank Kune}

Markkula, M. \& \& Kune, H. 2015. Toward Smart Regions: Highlighting the Role of Universities. In Lappalainen, P., Markkula, M. \& Kune, H. (Eds.) Orchestrating Regional Innovation Ecosystems. Aalto University in cooperation with Laurea University of Applied Sciences and Built Environment Innovations RYM Ltd.

Markkula, M., \& Kune, H. 2013. Horizon 2020: Regional Innovation Ecosystems - From Theory to Practice. In Open Innovation 2013. Brussels: European Commission Directorate-General for Communications, Networks, Content and Technology.

Markkula, M., Miikki, L., \& Pirttivaara, M. 2010. Uudenmaan liiton strategian toinen aalto. Helsinki: Helsinki-Uusimaa Regional Council.
Saunders, T., \& Baeck, P. 2015. Rethinking Smart Cities from the Ground Up. London: Nesta.

Viitanen, J., Markkula, M., \& Ripoll, C. R. 2013. Systemic Development of Regional Innovation Ecosystems - Modernizing the Triple Helix. In P. Lappalainen \& and M. Markkula (Eds.), The Knowledge Triangle: Re-Inventing the Future: 101-116. European Society for Engineering Education (SEFI), Aalto University, and Universitat Politecnica de Valencia.

Citation: Markkula, M., \& Kune, H. 2015. Making Smart Regions Smarter: Smart Specialization and the Role of Universities in Regional Innovation Ecosystems. Technology Innovation Management Review, 5(10): 7-15. http://timreview.ca/article/932

Keywords: smart specialisation, smart specialization, societal innovation, triple helix, quadruple helix, role of universities, smart cities, smart regions, innovation, innovation ecosystems 